\title{
CONTEXTUALIZAÇÃO CURRICULAR NUMA REDE DE ESCOLAS PORTUGUESAS: PROMESSA OU OPORTUNIDADE PERDIDA?
}

MARIA DO CÉU ROLDÃO SÍLVIA DE ALMEIDA

\section{RESUMO}

Na década de 1990, as políticas educativas internacionais e o campo teórico dos estudos curriculares conferiram centralidade ao debate sobre o currículo, conduzindo, nos países de tradição centralista, à passagem do paradigma do currículo uniforme, prescritivo, para um paradigma de contextualização curricular. Em Portugal, a introdução deste paradigma pelas politicas curriculares determinou a necessidade de prescrever às escolas a elaboração de um projeto curricular. A partir de então, a literatura tem demonstrado uma conceção das dinâmicas de construção, implementação e avaliação de projetos curriculares como documentos burocráticos, obedecendo a uma lógica da normatividade decretada, elaborados sobretudo para os painéis de avaliação externa das escolas, incapazes deste modo de implementar mudanças nas práticas curriculares. Neste texto, apresentam-se os resultados da avaliação de 12 projetos curriculares de uma rede colaborativa de escolas portuguesas com recurso à análise de conteúdo.

PALAVRAS-CHAVE CONTEXTUALIZAÇÃO CURRICULAR • AVALIAÇÃO CURRICULAR • PROJETOS CURRICULARES • POLITICA EDUCACIONAL. 


\title{
CONTEXTUALIZACIÓN CURRICULAR EN UNA RED DE ESCUELAS PORTUGUESAS: ¿PROMESA O OPORTUNIDAD PERDIDA?
}

RESUMEN

En la década de los 90, las políticas educativas internacionales y el campo teórico de los estudios curriculares debatían por encima de todo el currículo, lo que condujo en los países de tradición centralista al paso del paradigma del currículo uniforme y prescriptivo a un paradigma de contextualización curricular. En Portugal, la introducción de este paradigma por las políticas curriculares determinó la necesidad de prescribir a las escuelas la elaboración de un proyecto curricular institucional. Desde entonces la literatura ha demostrado una concepción de las dinámicas de construcción, implementación y evaluación de proyectos curriculares como si fueran documentos burocráticos, obedeciendo a una lógica de la normatividad decretada, elaborados sobre todo para los paneles de evaluación externa de las escuelas, incapaces de este modo de implementar cambios en las prácticas curriculares. En este texto, se presentan los resultados de la evaluación de 12 proyectos curriculares de una red colaborativa de escuelas portuguesas realizada teniendo en cuenta el análisis de contenido.

PALABRAS CLAVE CONTEXTUALIZACIÓN CURRICULAR • EVALUACIÓN CURRICULAR • PROYECTOS CURRICULARES • POLÍTICA EDUCATIVA.

\section{CURRICULUM CONTEXTUALIZATION IN A NETWORK OF PORTUGUESE SCHOOLS: A PROMISE OR A MISSED OPPORTUNITY?}

\begin{abstract}
In the 1990's, international educational policies, as well as the theoretical field of curriculum studies, gave centrality to the debate on curriculum. This led countries with a centralist tradition to shift from the paradigm of a uniform and prescriptive curriculum towards a paradigm based on curriculum contextualization. Following the latter, new curricular policies were introduced in the Portuguese system which determined that schools should develop their own curriculum plan. Since then, the literature on the subject has shown that the construction, implementation and evaluation dynamics of these curriculum plans have been conceived as bureaucratic documents, obeying a logic of normativity and being mostly designed to suit external evaluation panels that proved unable to implement change in curriculum practices. In this paper, the method of content analysis was used to present the results of the evaluation of 12 curriculum projects implemented in a collaborative network of Portuguese schools.
\end{abstract}

KEYWORDS CURRICULUM CONTEXTUALIZATION • CURRICULUM ASSESSMENT • CURRICULUM PROJECTS • EDUCATIONAL POLICIES. 


\section{INTRODUÇÃO}

Em Portugal, à semelhança de outros países europeus e no âmbito da Organização para a Cooperação e Desenvolvimento Econômico (OCDE), as políticas educativas e curriculares desenvolvidas a partir da década de 1990 têm vindo a sublinhar o papel da escola como espaço central da ação educativa e o papel do professor como ator principal desse processo, por meio de medidas de contextualização curricular, desde a introdução do projeto de Gestão Flexível do Currículo (PORTUGAL, 1997). Este projeto, de iniciativa ministerial mas lançado para todo o sistema, iniciou uma reflexão no sentido de fazer convergir a prescrição curricular nacional (Currículo Nacional) com a atribuição às escolas do poder de decisão quanto à contextualização e adequação desse currículo às suas situações particulares, corporizada num Projeto Curricular de Escola (PCE). O currículo tem sido assim cada vez mais entendido, na discursividade política, como uma construção participada por vários atores sociais, pelo menos de um ponto de vista retórico, em que se atribui mais autonomia à escola para conceção, desenvolvimento e avaliação dos PCEs em articulação com o currículo nacional. 
No contexto português, a literatura tem feito um balanço pouco positivo a respeito das dinâmicas de construção, implementação e avaliação destes projetos curriculares (ROLDÃO, 2005a, 2014; PACHECO; PEREIRA, 2007; MORGADO; MARTINS, 2008; MORGADO, 2011; GONÇALVES; MORGADO, 2013), assinalando as consequências que daí resultam em termos de desenvolvimento da autonomia das escolas e da adequação da ação profissional dos professores, bem como da pretendida melhoria das aprendizagens dos alunos.

Passados 20 anos da introdução do Projeto de Gestão Flexível do Currículo, e com a retoma de políticas de flexibilização curricular que está em curso na ação do atual poder político em Portugal, importa refletir de novo sobre as práticas de gestão curricular nas escolas. Daí a oportunidade para centrar a atenção na importância do PCE como instrumento de renovação e inovação das práticas pedagógicas e de construção da autonomia curricular do professor e da escola, uma vez que é no campo da ação curricular concreta e das práticas docentes que se jogam a qualidade educativa e o sucesso das aprendizagens.

Neste artigo, apresentam-se os resultados de uma análise de conteúdo de 12 PCEs de uma rede colaborativa de escolas portuguesas, que constituem parte dos resultados de uma investigação sobre as práticas de gestão curricular expressas nos seus respetivos projetos.

Tendo como referência a centralidade que este documento orientador assume como instrumento de gestão curricular contextualizada, tanto na literatura teórica como nas políticas curriculares, partimos das seguintes questões: como as escolas que têm um PCE já desenvolvido construíram, ou não, um modelo de gestão curricular? Que componentes e princípios teoricamente sustentados se identificam para construir um modelo de referência orientador da elaboração de PCEs? 


\section{ENQUADRAMENTO HISTÓRICO-CONCEPTUAL}

\section{AS POLÍTICAS CURRICULARES: DA UNIFORMIDADE À CONTEXTUALIZAÇÃO}

As políticas educativas internacionais do final do século $\mathrm{XX}$ (SKILBECK, 1990; ORGANISATION FOR ECONOMIC CO-OPERATION AND DEVELOPMENT - OECD, 1991, 1993, 1994, 1998, 1999) colocaram o currículo no centro do debate educativo, o que encontrou respaldo no campo teórico (CARMEN; ZABALA, 1991; SACRISTÁN, 1994; ZABALZA, 1992; HUTMACHER, 1992; ROLDÃO, 1995, 1998, 1999b, 1999c, 2000), conduzindo, nos países de tradição centralista, à passagem do paradigma do currículo uniforme, prescritivo, para um paradigma da contextualização curricular.

As medidas curriculares desde então implementadas têm vindo a acentuar a reorientação dos loci de decisão curricular, em resultado da complexidade dos contextos e populações que a universalidade da escolarização trouxe para o interior da escola nas sociedades democráticas, acentuando as pressões quer no sentido da contextualização e diferenciação curricular e pedagógica, quer no reforço de um núcleo curricular comum corporizado nos chamados currículos nacionais (OECD, 2013, 2014, 2016).

O debate em torno da responsabilidade acrescida da escola na gestão do seu trabalho curricular tem-se centrado assim quer na articulação deste nível de decisão com o nível central, anteriormente o único nos países de administração centralista como Portugal, quer em questões de organização e gestão contextualizada, nomeadamente concretizada em projetos próprios de cada escola, desejavelmente adequados a cada grupo de alunos e respetivos contextos, no sentido de melhorar o nível e a qualidade das aprendizagens curriculares pretendidas para todos (ROLDÃO, 2008).

\section{O CURRÍCULO ESSENCIAL COMUM (CORE CURRICULUM) E O BINÓMIO CURRICULAR}

As implicações organizativas deste processo de gestão do trabalho curricular da escola, com iniciativa e responsabilidades claramente acrescidas da instituição e dos professores, têm contudo sido menos discutidas na comunidade de 
docentes, largamente marcada por uma cultura prescritiva e pouco socializada numa cultura de iniciativa e de auto e hetero-regulação.

Trata-se, assim, de recordar que o currículo é, na sua génese e mutabilidade, uma construção social (GOODSON, 1988, 2005; YOUNG, 1998). Contudo, gerado no seio de uma instituição especificamente curricular na sua natureza - a escola -, o currículo é também, no seu modus operandi (que na realidade lhe dá forma e regula o seu conteúdo e modo de passagem), uma produção organizacional, largamente conformada e imbricada nos mecanismos organizacionais que a escola configura (ROLDÃO, 2000, 2001, 2016; BARROSO, 1995, 1997; PERRENOUD, 1997, 2000).

A década de 1990 trouxe consigo a necessidade de diferenciar dois grandes níveis de decisão curricular: o nível central que estabelece o core curriculum; e o nível de decisão contextual, sustentado na maior autonomia das escolas na operacionalização e gestão contextualizada do currículo. A este processo tem sido atribuída a designação de binómio curricular (ROLDÃO, 2000, 2003a, 2003b, 2005a). Contudo, sua configuração é bem diversa em países de tradição centralista ou em países com percursos históricos de grande autonomia local. Daí que se deve acautelar a tentação de assimilar genericamente a expressão currículo nacional a core curriculum. Nos países tradicionalmente centralizados, o currículo nacional era, desde o início, o único que existia. O novo nesses contextos é a autonomia curricular das escolas, que causa perturbação por justamente romper o carácter único do currículo prescrito nacionalmente. Já nos países de grande autonomia local, como os nórdicos e os anglo-saxónicos, ocorre o inverso: o currículo nacional surge como um fator de regulação comum à tradicional diversidade de opções que as escolas podiam adoptar, normalizadas apenas por avaliações externas, aparecendo por isso como mais constrangedor para as escolas.

Malcolm Skilbeck (1994, p. 93) define assim o conceito de core curriculum, situando historicamente a sua necessidade política em face da massificação escolar e consequente diversidade dos públicos: 
1 AUSTRALIAN CURRICULUM DEVELOPMENT CENTRE. Core curriculum of the Australian schools: what it is and why it is needed. Canberra: Curriculum Development Centre, 1980
- Em síntese, o core curriculum consiste naquelas aprendizagens consideradas básicas e essenciais para todos: básicas porque oferecem um suporte sobre o qual as aprendizagens subsequentes podem construir-se e proporcionam o domínio das ferramentas metodológicas que permitem a cada um prosseguir a sua própria aprendizagem.

- São essenciais na medida em que apetrecham os aprendentes para uma participação satisfatória e efectiva na vida social e cultural.

- Trata-se daquela dimensão do currículo total que é genericamente comum a todas as escolas, definida em parceria pelos decisores centrais e locais, e depois reinterpretada por cada escola.

As dimensões do core curriculum referem-se necessariamente ao máximo das aprendizagens comuns a garantir, e não à ideia simplificadora de mínimos que empobreceriam o currículo. Em texto do Australian Curriculum Development Centre $\left(1980^{1}\right.$ apud SKILBECK, 1994, p. 97), estabelece-se que esse denominador comum nacional - o core curriculum - deverá conter a prescrição nacional de aspetos comuns quanto a:

- áreas de conhecimento e experiência a abordar;

- processos de aprendizagem a dominar;

- $\quad$ situações e contextos de aprendizagem a experienciar.

\section{A COMPLEXA OPERACIONALIZAÇÃO DO BINÓMIO CURRICULAR}

No debate curricular e político sobre a proclamada deslocação de níveis de decisão para a escola e professores, tem faltado situar com clareza os dois fatores que condicionam em absoluto uma tal deslocação: de um lado, a própria natureza dos conteúdos curriculares e do trabalho do seu desenvolvimento (vulgo o como, os métodos didácticos, os modos dominantes da prática docente, o acto de ensinar e ensinar o quê, tal como é vivido nas escolas, bem como os dispositivos - ou ausência deles - estabelecidos para o trabalho do aluno); e, de outro, a incontornável estruturação que é dada ao currículo 
pelo esqueleto organizacional da instituição escolar, espantosamente imutável há quase dois séculos: a organização dos tempos, dos espaços, da produção letiva, do ato - aliás atos segmentares - de ensinar (ROLDÃO, 2001; BENAVOT; BRASLAVSKY, 2007).

Assim, o desiderato político-curricular que permite compreender as políticas que anteriormente designamos como estruturadas em termos de "binómio curricular" orientou-se no sentido de induzir as seguintes mudanças:

- um equilíbrio entre o core curriculum - a referência central - e a autonomia das escolas no sentido de promover esse core curriculum numa variedade de formatos contextuais relacionados com as diversidades dos estudantes e dos seus contextos - adopção de um binómio curricular (ROLDÃO, 2003b);

- o abandono quer de um currículo único e uniforme para ser "cumprido" (tradição centralista), quer de uma diversidade de currículos de qualidade desigual, correspondendo aos níveis e contextos das escolas (tradição descentralizada) em favor de "um core curriculum comum para todas as escolas [...] reinterpretado por essas escolas"(SKILBECK, 1994, p. 96, grifos nossos);

- a adopção da organização do currículo por competências no sentido de viabilizar a diversidade de abordagens.

Entende-se aqui competência no sentido de mobilização integrada de conhecimento, experiência e disposições que capacitam o aprendente a confrontar-se com e a responder a situações complexas e contextuais (TARDIF, 1996; LE BOTERF, 1994).

O papel das competências no desenvolvimento do binómio curricular que enquadra a decisão sobre o currículo nesses dois níveis (central comum e local diverso), de forma articulada, traduz-se nas seguintes dimensões que a competência permite desenvolver no interior do currículo:

- competência como organizador curricular do conhecimento - por oposição a simples sequências de temas ou listas de conteúdos; 
- competência como mobilizador dos diferentes conhecimentos das disciplinas em torno da construção do currículo como um todo;

- competência como transformação de corpos estáticos de saberes em saberes-em-uso (ROLDÃO, 1995).

Essa mudança de paradigma configurou assim, no caso português, a prescrição de um binómio curricular, que se traduziu na definição de aprendizagens curriculares essenciais comuns - core curriculum (SKILBECK, 1990) -, o que ficou expresso no que se denominou por Currículo Nacional do Ensino Básico - Competências essenciais (PORTUGAL, 2001b, revogado em 2011), articuladas com a diversidade de PCEs, a cargo das escolas e correspondentes a contextos diferenciados (ROLDÃO, 1999b, 2000, 2003a).

\section{AS DIFICULDADES DAS POLÍTICAS DE BINÓMIO CURRICULAR EM FACE DA PERSISTÊNCIA DO FORMATO ORGANIZACIONAL DA ESCOLA - DESENVOLVIMENTOS RECENTES}

Passadas duas décadas sobre as políticas anteriormente caracterizadas como binómio curricular, observa-se um duplo efeito, identificado em documentos internacionais (UNITED NATIONS EDUCATIONAL, SCIENTIFIC AND CULTURAL ORGANIZATION - UNESCO, 2015; OECD, 2014): por um lado, os currículos nacionais em formato core curriculum (os dos países com tradição curricular localista, nomeadamente os nórdicos), nas sucessivas revisões após as primeiras versões dos anos 1990, exibem alguma tendência para se tornarem mais extensos e mais detalhados (FINNISH NATIONAL BOARD OF EDUCATION - FNBE, 2016). Contudo, nesses sistemas, nomeadamente os nórdicos, tal reforço, também expressando a pressão da competição em estudos internacionais, de que se destacam as sucessivas edições do Programme for International Student Assessment (PISA), não se traduziu em perda significativa da tradição autonómica das escolas como gestoras efetivas dos seus currículos, mesmo quando mais pesados, na medida em que a cultura escolar e a cultura docente nestas sociedades são fortemente assentes na autonomia da gestão local do currículo, por meio dos poderes 
locais e postos em acção pelas escolas e seus professores. $\mathrm{Na}$ Finlândia assistimos, desde 2015-2016, a um outro avanço nesse caminho de autonomia gestionária, instituindo para o nível da escolaridade básica (1-9) uma gestão do currículo nacional organizada em torno de projetos curriculares temáticos, geridos pelas equipas de professores, articulados com espaços curriculares disciplinares que permanecem no espaço curricular, mas em menor percentagem (FNBE, 2016).

Por outro lado, nos países de tradição administrativa centralista (Portugal, Espanha, França, Itália), as tentativas de criação de dinâmicas de gestão contextualizada do currículo pelas escolas não ganharam a projeção desejada na operacionalização efetiva de um nível local de decisão curricular situado nas escolas. No caso português, este nível de decisão traduzia-se na produção dos já referidos PCEs (objeto da investigação avaliativa que neste texto se descreve), por sua vez, desenvolvidos em PCT - projetos curriculares de turma (DL 6/2001). Contudo, a estrutura tradicional da organização da gramática escolar (TYACK; CUBAN, 1995; CUBAN, 1990) fez subsumir ou tornar pouco operantes os processos de decisão tentados, que adiante se descrevem. Tal esbatimento foi acompanhado de decisões políticas centrais do ciclo político seguinte na rotação partidária, que desvalorizavam esta linha da autonomia curricular, reforçando a dimensão do controlo central nomeadamente via exames externos em todos os ciclos, políticas que se situaram entre 2011 e 2015.

Mas importa sublinhar que estes patamares de decisão curricular da escola foram largamente postos em causa, mesmo antes da viragem político-partidária do poder central, pelas próprias escolas e professores que transformaram os projetos curriculares (PCE e PCT) em documentos de registo meramente burocráticos, esvaziados da sua finalidade de gestão contextualizada do currículo e do seu desenvolvimento nas práticas de ensino, como se definiam na sua intencionalidade declarada (ROLDÃO, 2005a). A investigação destaca também o papel da ação dos professores no processo curricular, tornando essa uma linha de necessidade de intervenção futura no plano do currículo (OECD, 2014; HATTIE, 2009) 
A adoção da designação Currículo Nacional para o currículo essencial comum, que fazia grande sentido por exemplo nos países nórdicos pela sua novidade, em Portugal nunca foi entendida como uma das partes do referido binómio de decisões curriculares, já que o referente único da cultura curricular portuguesa, muito centralista, sempre foi, por definição, o nacional, do qual emanam as prescrições que estão enraizadas profundamente no agir e no pensar das escolas e professores.

Os decisores políticos portugueses atuais - de novo no âmbito da rotação político-partidária dos governos, o que em Portugal, lamentavelmente, condiciona excessivamente as macropolíticas educativas que deviam ser socialmente consensualizadas e desenvolvidas em médio prazo -, defendendo novamente uma política curricular atualizada, convergente com as tendências internacionais, de reforço da dimensão contextual e da necessidade de assegurar melhores níveis de qualidade de ensino e de sucesso das aprendizagens curriculares (OECD, 2015; UNESCO, 2014, 2015; ANANIADOU; CLARO, 2009), recolocaram desde 2015 na agenda política a discussão da questão da gestão curricular e correlativa contextualização e flexibilização do currículo, decorrendo em Portugal neste momento diversos desenvolvimentos dessa retoma em curso, que se defrontam com idênticas resistências da cultura de escola e de professores, que a investigação internacional também tem evidenciado (OECD, 2013, 2014; HATTIE, 2009).

No plano internacional, importa ainda considerar que os desenvolvimentos mais recentes retomam a mesma problemática (UNESCO, 2014, 2015; OECD, 2017), largamente centrada na discussão das dimensões essenciais dos currículos e nas estratégias do seu "emagrecimento" - configurando de novo a discussão do core curriculum e das políticas de maior eficácia da gestão contextualizada do currículo pelas escolas, como se documenta nos working papers já acessíveis do Projeto Skills and Education 2030 (OECD, 2017).

No âmbito da OCDE, e em outras sedes de investigação curricular, discute-se neste momento a reconfiguração de políticas curriculares. Constituem temas centrais desse debate: 
- a procura do sucesso alargado das aprendizagens;

- a seleção das aprendizagens curriculares essenciais e consequente "emagrecimento curricular";

- a articulação do currículo com competências transversais;

- a maior adequação do currículo a novas necessidades sociais, políticas e económicas (OECD, 2017; UNESCO, 2015, 2016; ANANIADOU; CLARO, 2009);

- a maior centralidade atribuída à ação e ao profissionalismo docente na construção de um currículo de sucesso (OECD, 2014).

Parte desta permanência, na segunda década do milénio, da problemática da contextualização curricular, originada nos anos 1980 e 1990, pode explicar-se pela imutabilidade relativa das estruturas organizativas em que o currículo se desenvolve. A escola tem mantido até hoje a estrutura organizativa e as lógicas de ensino que a instituíram em épocas passadas, quando os públicos eram muito mais restritos e homogéneos e as finalidades menos ambiciosas para a maioria, embora mais seletivas para um leque reduzido da população. É nessa lógica que toda a orgânica da escola ainda funciona, bem como as correlativas visões da ação dos professores e suas metodologias de ensino dominantes (ROLDÃO, 2012). Situam-se também neste domínio toda a teorização e múltiplas contradições associadas às orientações de política educativa, largamente consensuais no plano discursivo, no sentido da chamada "escola inclusiva" (CLARK, 1999; AINSCOW, 1991).

Emergem na última década movimentos que iniciam abordagens consistentes a esta ruptura no modo organizacional e pedagógico de fazer passar o currículo com a eficácia que o deve legitimar e que não tem tido, tomando como referentes os níveis de insucesso persistentes (ROLDÃO, 2016). Destacam-se o Projeto 2020, desenvolvido por uma rede de colégios na Catalunha, e os desenvolvimentos já referidos do currículo da Finlândia (RED JESUÏTES EDUCACIÓ, 2015; FINNISH NATIONAL BOARD OF EDUCATION - NBFE, 2016).

É dessa teia de contradições que aqui nos ocupamos. Considerou-se pertinente desenvolver um estudo centrado 
na avaliação de 12 PCEs apresentados por uma rede de escolas no ano letivo de 2016/2017. Neste estudo, está a ser desenvolvida uma avaliação consistente dos PCEs, acompanhada de inquirição dos atores, não só para clarificar de que modos este quadro teórico-curricular e político foi apropriado pelos professores, como também para produzir conhecimento útil para o atual desenvolvimento de renovadas políticas de autonomia curricular das escolas.

\section{AUTONOMIA DAS ESCOLAS: DO PROJETO EDUCATIVO AO PROJETO CURRICULAR}

Em Portugal, Espanha e França, desde o final dos anos 1990 até o início do século XXI, conforme anteriormente sublinhamos, a literatura sobre a gestão curricular e PCEs, incluindo modelos de referência para o desenvolvimento curricular nas escolas, foi muito profícua. Importa assim situar a emergência e os entendimentos do omnipresente conceito de projeto, designadamente convocado no dispositivo Projeto Educativo (PE), bem como sobre o conceito de autonomia que lhe está associado, dos quais decorre o PCE, objeto desta investigação. A definição concetual impõe-se pela pluralidade de sentidos que encerram estes conceitos.

Desde o final dos anos 1980, afirma-se, na literatura, que vivemos numa civilização de projetos (BARBIER, 1991) que se tornaram numa espécie de "micro-ideologia da ação" quotidiana (BARROSO, 1992). O termo projeto tem origem nas teorias da administração, a partir do momento em que a planificação e gestão estratégica foram consideradas práticas essenciais do sucesso das empresas.

A planificação estratégica foi criada como um "processo de conceber um futuro desejado, bem como os meios reais para o alcançar” (GODET, 1985, p. 80). A planificação está associada à prospetiva como "uma reflexão para iluminar a ação presente, à luz dos futuros possíveis (GODET, 1989, p. 80). A premência de preparar o futuro levou a que, na primeira fase da planificação, se estabeleça um projeto para a empresa, iniciando com a definição de um diagnóstico para detetar as ameaças e as oportunidades do ambiente estratégico, para identificar as forças e fraquezas dos recursos 
da empresa (humanos, técnicos, comerciais e financeiros) (GODET, 1985, p. 171).

A realização do projeto implica a coexistência de uma lógica do desejo que valoriza a dimensão simbólica (missão, visão, valores) e a lógica da ação que sublinha a dimensão operatória (BARROSO, 1992, p. 28) depois da elaboração do diagnóstico, identificando as estratégias de concretização a curto e médio prazos.

As teorias da administração passaram para o mundo educacional. Nos anos 1980, nos países da OCDE e das Comunidades Europeias (BARROSO; SJORSLEV, 1990, p. 121), as autoridades administrativas associaram a autonomia das escolas à elaboração de um projeto, neste caso do PE.

No contexto português, o Decreto-Lei n. 43/89, que consagra a autonomia da escola, relaciona-a com a formulação do PE:

A autonomia da escola concretiza-se na elaboração de um projeto educativo próprio, constituído e executado de forma participada, dentro de princípios de responsabilização dos vários intervenientes na vida escolar e de adequação a características e recursos da comunidade em que se insere. (PORTUGAL, 1989, preâmbulo)

O PE é, assim,

[...] um instrumento de planificação de longo prazo que enquadra a definição e a formulação das estratégias de gestão e do qual decorrem os planos operacionais de médio e de curto prazo. (BARROSO, 1992, p. 30)

O surgimento normativo (2001) do PCE, no âmbito do Decreto n. 6/2001 (PORTUGAL, 2001a), que geria a desejada nova política curricular, teoricamente em binómio, apresentava assim um desfasamento temporal em face da prescrição de produzir, no âmbito da autonomia de gestão da escola, um PE (1989). Este facto duplicou a dificuldade de se entender o PCE como o âmago do PE, e inserido nele. Na verdade, e apesar das normas o aconselharem, o Projeto Curricular de Escola foi visto nas escolas como uma díade documental, e não como um documento integrado. 
Das indicações para a elaboração do PCE, destaca-se desde logo a conformidade com o PE, no sentido de "contribuir para a continuidade e coerência da atuação educativa de toda a equipa de professores da escola" (CACHAPUZ et al., 2004, p. 81; COSTA; RAMOS, 2004, p. 88).

O PCE deverá operacionalizar a parte central do PE que são as orientações pedagógico-curriculares, dada a natureza da escola como uma instituição curricular no sentido em que sua existência se justifica: por uma finalidade curricular - garantir uma passagem/apropriação de saberes tidos como necessários para certo tipo de competências numa dada época e contexto - e pela especificidade processual/metodológica da sua atuação no desenvolvimento curricular dessa finalidade, por meio da escolha e estruturação de modos de fazer aprender (métodos de ensino e organização) aquilo que socialmente se considera que deve ser aprendido (ROLDÃO, 2000, p. 4).

Percebe-se, assim, a centralidade do PCE, pois, em conjunto com o PE, constitui um meio fundamental para a construção da autonomia curricular da escola e dos professores, destinado a proporcionar a melhoria da qualidade das aprendizagens e do sucesso educativo dos alunos, ao ser adaptado precisamente aos respetivos contextos. Este documento potencia a gestão curricular das escolas/professores com o objetivo de partilhar e fixar estratégias comuns sobre o quê, quando e como avaliar (GIMENO, 1989, p. 14). Reconhece-se, assim, a importância deste instrumento para a autonomia das escolas no sentido que implica o processo de decisão e deliberação curriculares ao nível de cada instituição educativa favorável à melhoria das aprendizagens (MORGADO, 2003, 2011).

Na literatura o projeto curricular é concebido como um instrumento de gestão pedagógica-curricular contextualizador, que reúne pelo menos duas caraterísticas: reconstrutor do currículo nacional, no sentido de se adequar às características dos contextos locais da sua aplicação; e fomentador de uma cultura de reflexão sobre os processos de ensino, o que apenas é possível por meio do trabalho cooperativo entre os professores (CARMEN; ZABALA, 1991; PACHECO, 1998; ROLDÃO, 1999b; PACHECO; MORGADO, 2002; RODRIGUES; SÁ-CHAVES, 2004; COSTA; RAMOS, 2004). 
São estas ideias-chave que atravessam as definições, por exemplo, de Carmen e Zabala (1991, p. 16) ao determinarem o PCE como um

[.... conjunto de decisões articuladas, partilhadas pela equipa docente de uma escola, tendentes a dotar de maior coerência a sua atuação, concretizando as orientações curriculares de âmbito nacional em propostas globais de intervenção pedagógico-didática adequadas a um contexto específico,

ou de Roldão (1999a, p. 44) ao referir que

[...] por projeto curricular entende-se a forma particular como, em cada contexto, se reconstrói e se apropria um currículo face a uma situação real, definindo opções e intencionalidades próprias, e construindo modos específicos de organização e gestão curricular, adequados à consecução das aprendizagens que integram o currículo para os alunos concretos daquele contexto.

A gestão curricular como um processo de tomada de decisões, como já se afirmou anteriormente, inclui dois grandes níveis de decisão curricular: o nível central, que se relaciona com o currículo nacional e os modos de ensinar delineados pela administração central; e o nível institucional, que diz respeito à contextualização curricular da escola tendo como referência o currículo nacional que se materializa num PCE. Nestes dois níveis de deliberação curricular, é possível identificar seis campos de decisão que são comuns, embora trabalhados com níveis de operacionalização diversos que sistematizamos no Quadro 1. 
QUADRO 1 - Níveis e campos de decisão curricular

\begin{tabular}{|c|c|c|}
\hline CAMPOS DE DECISÃO & $\begin{array}{l}\text { NÍVEL: ADMINISTRAÇÃO } \\
\text { CENTRAL }\end{array}$ & NÍVEL: INSTITUCIONAL - ESCOLA \\
\hline $\begin{array}{l}\text { 1. Filosofia distintiva e oferta } \\
\text { educativa }\end{array}$ & $\begin{array}{l}\text { Função social e educativa da } \\
\text { escola. }\end{array}$ & $\begin{array}{l}\text { - A partir do diagnóstico e da identidade descrita } \\
\text { no PE: fundamentar a filosofia educativa e a oferta } \\
\text { educativa. }\end{array}$ \\
\hline 2. Opções e prioridades & $\begin{array}{l}\text { Opções e prioridades } \\
\text { curriculares a nível nacional } \\
\text { (p.e. melhorar o desempenho } \\
\text { na língua materna em } 30 \% \\
\text { no sistema; ou dar prioridade } \\
\text { à aprendizagem científica e } \\
\text { tecnológica). }\end{array}$ & $\begin{array}{l}\text { - Em que aspetos curriculares - core curriculum - } \\
\text { investir mais, em face das características e } \\
\text { necessidades da população; } \\
\text { - Que conteúdos de aprendizagem não contidos } \\
\text { no core curriculum integrar e por quê. Oferta de } \\
\text { aprendizagens em campos não cobertos pelo } \\
\text { currículo nacional. }\end{array}$ \\
\hline $\begin{array}{l}\text { 3. Organização das } \\
\text { aprendizagens }\end{array}$ & $\begin{array}{l}\text { Competências à saída de } \\
\text { sistema educativo. } \\
\text { Corpo de aprendizagens } \\
\text { requerido para o domínio dessas } \\
\text { competências que devem ser } \\
\text { adquiridas por todos os alunos } \\
\text { nas disciplinas (ou outros } \\
\text { formatos). }\end{array}$ & $\begin{array}{l}\text { - Articulação entre as atitudes e valores, } \\
\text { capacidades e aptidões e conhecimentos definidos } \\
\text { no Perfil do aluno: (ex.: redigir relatório científico } \\
\text { nas competências - então na sala deve conter um } \\
\text { momento de realização do mesmo); } \\
\text { - Modos de organização das aprendizagens } \\
\text { diversificados: áreas disciplinares e espaços } \\
\text { multidisciplinares; (i.e. oficinas de práticas } \\
\text { profissionais ou tradicionais). }\end{array}$ \\
\hline $\begin{array}{l}\text { 4. Métodos e estratégias de } \\
\text { ensino e avaliação }\end{array}$ & $\begin{array}{l}\text { Metodologias de ensino que se } \\
\text { valorizam face às competências } \\
\text { socialmente necessárias. } \\
\text { Orientações sobre os } \\
\text { procedimentos e modalidades } \\
\text { de avaliação. }\end{array}$ & $\begin{array}{l}\text { - Estratégias de ensino que a escola privilegia em } \\
\text { função dos valores que assume como sua proposta } \\
\text { educativa (métodos, técnicas, recursos); } \\
\text { - Princípios/Orientações sobre a avaliação } \\
\text { das aprendizagens dos alunos (modalidades, } \\
\text { instrumentos, campos). }\end{array}$ \\
\hline $\begin{array}{l}\text { 5. Modos de funcionamento } \\
\text { e organização da escola e } \\
\text { das aulas }\end{array}$ & $\begin{array}{l}\text { Princípios orientadores das } \\
\text { opções organizativas das } \\
\text { aprendizagens. }\end{array}$ & $\begin{array}{l}\text { Opções organizativas da escola, em termos de } \\
\text { enquadramento das atividades de aprendizagem: } \\
\text { Critérios pedagógicos de constituição das } \\
\text { turmas com organização flexível de tempos e } \\
\text { espaços, dentro das turmas (por exemplo, grupos } \\
\text { temporários de alunos); variação dos tempos de } \\
\text { apoio; } \\
\text { Justificação da unidade de tempo de referência e } \\
\text { criar dispositivos para a sua flexibilização; } \\
\text { Organização de horários e distribuição de serviço } \\
\text { docente em termos de maximizar as aprendizagens } \\
\text { dos alunos; } \\
\text { Recomendações e critérios sobre a comunicação e } \\
\text { reuniões com os pais. } \\
\text { Princípios enquadradores das opções organizativas } \\
\text { do trabalho dos professores: } \\
\text { - Estabelecimento de tempos e espaços para o } \\
\text { trabalho colaborativo. }\end{array}$ \\
\hline $\begin{array}{l}\text { 6. Avaliação do resultado } \\
\text { de cada uma das opções do } \\
\text { projeto curricular }\end{array}$ & $\begin{array}{l}\text { Avaliação das aprendizagens } \\
\text { do core curriculum conseguidas } \\
\text { a nível nacional através } \\
\text { de instrumentos externos } \\
\text { adequados. } \\
\text { Reformulação do core } \\
\text { curriculum quando se revele } \\
\text { inadequado, insuficiente ou } \\
\text { rígido face às necessidades de } \\
\text { formação dos cidadãos. }\end{array}$ & $\begin{array}{l}\text { - Avaliação das aprendizagens propostas no projeto } \\
\text { curricular da escola (interna e externa); } \\
\text { - Construção de instrumentos de avaliação } \\
\text { adequados; } \\
\text { - Avaliação do trabalho curricular desenvolvido nas } \\
\text { turmas, nos órgãos intermédios e nos órgãos de } \\
\text { gestão. }\end{array}$ \\
\hline
\end{tabular}

Fonte: Adaptado de Roldão (1999a, p. 60-61).

\section{METODOLOGIA}

Privilegiamos uma metodologia de cariz qualitativo e interpretativo com algumas caraterísticas da investigação-ação para este estudo das lógicas atribuídas pelas escolas à construção e uso dos PCEs - de que aqui se analisa uma parte dos dados. 
Numa primeira fase, recolheram-se os PCEs de uma rede portuguesa de escolas. De um total de cerca de 40 escolas, apenas 12 tinham elaborado o PCE, que foi submetido a uma análise de conteúdo.

Numa segunda fase, com o objetivo de aprofundar o estudo sobre as práticas de gestão curricular, foram selecionadas três escolas com projetos curriculares mais desenvolvidos para a aplicação de entrevistas em focus group. Os grupos foram constituídos por professores(as) que assumem cargos de lideranças intermédias como os coordenadores de departamento e/ou de ciclo (no caso do $1^{\circ}$ ciclo de escolaridade do ensino básico), os coordenadores dos diretores de turma e alguns diretores de turma. As lideranças intermédias têm como uma das suas funções liderar as equipas que, entre outros objetivos, implementam o projeto curricular no quotidiano dos agrupamentos de escolas.

Tendo em conta os resultados da análise de conteúdo, do focus groups, duma revisão da literatura sobre gestão curricular, estamos a atualizar a obra Gestão curricular: fundamentos e práticas (Roldão, 1999b) no sentido de disponibilizarmos um referencial com orientações para a elaboração de PCEs. Neste texto apresenta-se apenas a avaliação parcial que resulta da análise de conteúdo dos PCEs.

\section{ANÁLISE DE CONTEÚDO}

A análise de conteúdo dos projetos curriculares foi realizada com base num sistema de categorias misto, de natureza dedutiva e indutiva, definido com base no conhecimento teórico produzido sobre a problemática em questão e a partir de uma leitura flutuante do corpus em estudo. O livro Gestão curricular: fundamentos e práticas (ROLDÃO, 1999b) permitiu identificar um conjunto de decisões curriculares (ver Quadro 1) que guiou a construção do sistema de categorias dos PCEs das escolas em análise.

Na identificação das categorias, aplicámos as duas funções de análise de conteúdo enunciadas por Bardin (2006[1977]), ou seja, a função de "administração de prova", sob a forma de orientações que conduzem a leitura dos documentos, e a função heurística decorrente da leitura daqueles 
e do objetivo da nossa investigação. Como unidade de registo, optámos pelo recorte ao nível semântico e, como unidade de contexto, privilegiamos a frase. Já como unidade de enumeração das categorias temáticas, privilegiou-se a presença/ ausência.

O sistema integrou um total de 31 categorias (Anexo 1) e a análise foi realizada com o auxílio do programa MAXQDA 12.3.1, que permite o recurso aos métodos mistos, possibilitando a introdução/gestão, para além de um sistema de categorias, de uma base com "variáveis de documento" qualitativas e quantitativas com informações de caráter mais descritivo sobre o corpus em análise. A forma mais usual de utilização destas variáveis é no recurso aos métodos mistos (KUCKARTZ, 2014). Assim, é possível "ativar"/selecionar determinadas variáveis quantitativas e analisar os resultados em função delas. Por exemplo, "ativando" a variável "número de alunos da escola”, poderíamos perceber o que distinguia as escolas com mais e menos alunos em relação às categorias em análise.

Neste caso, procedemos a uma aplicação diferente destas "variáveis de documento" (Anexo 2), mobilizando-as como informações relacionadas/adicionais ao sistema de categorias de forma a complementarem a sua análise.

\section{RESULTADOS}

\section{CRÍTICA DA FONTE}

De forma geral, o registo escrito dos PCEs está muito vinculado aos documentos legais que os enquadram, podendo incluir longas citações da legislação ou reprodução de partes. Os conceitos do discurso das políticas curriculares internacionais, replicados nos normativos legais das políticas curriculares nacionais, como "trabalho colaborativo", "gestão curricular contextualizada" ou "diferenciação pedagógica" não operacionalizados em medidas concretas, multiplicam-se nos PCEs e parecem remeter para um discurso retórico, possivelmente induzido pela avaliação externa das escolas por não ser suportado, na maioria dos casos, por medidas concretas. Essa ausência de operacionalização pode ainda 
significar o "efeito transformador" falacioso da "bondade dos princípios” (BARROSO, 2014) que consubstancia um equívoco recorrente nas práticas educativas, ao se acreditar que determinados conceitos/princípios enunciados nos documentos reguladores conferem aos seus destinatários capacidade de ação.

De referir ainda que nos PCEs acumula-se uma lista de informações/definições que ora enquadram disposições normativas para os docentes ou para a elaboração de documentos pedagógicos, como guiões para elaboração do Projeto Curricular de Turma; ora abrangem especialmente a organização da escola, como a descrição do serviço de Psicologia e Orientação Escolar (Quadro 2). O que inscreve os PCEs entre o registo do regulamento e do relatório, de demonstrar à tutela ou à comunidade educativa, por exemplo, os serviços que a escola dispõe ou os apoios educativos que disponibiliza.

QUADRO 2 - Lista de informações/definições dos Projetos Curriculares de Escola/agrupamento

\begin{tabular}{|c|c|}
\hline DISPOSIÇÕES NORMATIVAS PARA OS DOCENTES & DISPOSIÇÕES SOBRE A ORGANIZAÇÃO DA ESCOLA \\
\hline $\begin{array}{l}\text { - Critérios de nomeação da coordenação das estruturas de } \\
\text { orientação educativa (ex.: critérios de nomeação do diretor } \\
\text { de turma, coordenador dos cursos profissionais, etc.). } \\
\text { - Perfis de cargos (ex.: perfis dos professores titulares } \\
\text { de turma/diretores, de turma/coordenadores, de } \\
\text { departamento, etc.). } \\
\text { - Cargos da coordenação das estruturas de orientação } \\
\text { educativa e tempo da componente letiva e não letiva } \\
\text { (cargos e redução da componente letiva). } \\
\text { - Guiões (ex.: guião para elaboração do Projeto Curricular } \\
\text { de Turma; guião para elaboração do Dossier Pedagógico } \\
\text { dos Cursos Profissionais/Vocacionais/Educação e } \\
\text { Formação, etc.). }\end{array}$ & $\begin{array}{l}\text { - Estruturas de orientação educativa (ex.: enumeração dos } \\
\text { departamentos curriculares e das suas funções). } \\
\text { - Serviços (ex.: descrição do funcionamento do Serviço de } \\
\text { Psicologia e Orientação Profissional, etc.). } \\
\text { - Educação especial (ex.: definição do conceito de NEE; } \\
\text { das unidades de apoio, das adequações no processo de } \\
\text { avaliação, etc.). } \\
\text { - Componente de apoio à família (pré-escolar) (ex.: horário } \\
\text { disponivel). } \\
\text { - Centro para a Qualificação e o Ensino Profissional (ex.: } \\
\text { atividades e funções). } \\
\text { - Associação de Pais (ex.: a sua existência por escola do } \\
\text { agrupamento e atividades). } \\
\text { - Descrição de espaços (ex.: descrição da sala de } \\
\text { informática). } \\
\text { - Assistentes operacionais e técnicos (ex.: descrição das } \\
\text { funções). } \\
\text { - Exames nacionais (ex.: descrição dos anos dos exames). } \\
\text { - Calendário escolar (ex.: descrição do início e fim do ano } \\
\text { letivo e períodos de férias). } \\
\text { - Substituição de aulas (ex.: procedimentos em caso de } \\
\text { permuta). } \\
\text { - Mudança de turma ou de estabelecimento de ensino do } \\
\text { grupamento (ex.: procedimentos e critérios de aceitação). } \\
\text { - Pedidos de transferência provenientes de outros } \\
\text { estabelecimentos de ensino (ex.: critérios de aceitação). } \\
\text { - Apoios educativos (ex.: descrição e objetivos). } \\
\text { - Transição e retenção de ciclo (ex.: critérios). }\end{array}$ \\
\hline
\end{tabular}

Fonte: 12 Projetos Curriculares de Escola/agrupamento de uma rede de escolas portuguesas. 
2 Não citamos excertos de texto exemplificativos da análise dos resultados para garantir o anonimato das escolas que foram objeto do presente estudo.

\section{FILOSOFIA DISTINTIVA E OFERTA EDUCATIVA}

O nível de decisão curricular sobre a filosofia distintiva e oferta da escola está praticamente ausente dos PCEs. A sua maioria não apresenta uma reflexão crítica do diagnóstico do PE na perspetiva da ação pedagógico-curricular da escola em face do contexto e inicia com a descrição das matrizes curriculares por ciclos de ensino ou pelo calendário escolar. Apenas um PCE reproduz duas tabelas do PE - contendo a população escolar por ciclo e estabelecimento de ensino, o número de docentes por ciclo e cargo pedagógico e o número de assistentes técnicos e operacionais - que não são acompanhadas por um texto crítico.

Como consequência, as linhas de adequação da oferta educativa com base no diagnóstico do PE não estão presentes nos PCEs em análise. À exceção de quatro PCEs, a oferta educativa apenas é deduzida a partir da enumeração das matrizes curriculares que em alguns projetos ocupa uma parte substancial do espaço (até um máximo de 14 páginas).

A dimensão simbólica do PCE, designadamente os valores, a visão da escola tendo como referência o PE, está completamente desvalorizada no corpus em análise. Assim, ficam por ser colocadas perguntas como: que pretende esta escola alcançar a curto e a médio prazos? Que pretende melhorar na sua imagem e no seu serviço? Qual é o "rosto da escola" em que ela se quer rever no futuro?

Porém, a filosofia e metodologias de ensino que as escolas valorizam como estratégia geral a adotar pelos departamentos curriculares ou pelos professores ao nível da sala de aula são, de alguma forma, concebidas em cinco PCEs que privilegiam a diferenciação curricular como princípio organizador do currículo a ser transmitido. ${ }^{2}$

Nos restantes PCEs, a diferenciação curricular é ainda invocada, mas em contextos específicos, fazendo depender a sua operacionalização destes, isto é, a partir da avaliação diagnóstica e/ou dos apoios educativos, destacando-se ainda um PCE que, aos dois contextos anteriores, acrescenta a supervisão pedagógica. 


\section{AS OPÇÕES E PRIORIDADES}

As opções/áreas prioritárias selecionadas pelas escolas para a melhoria da ação educativa e desejavelmente articuladas com as dos PEs não constam da maioria dos PCEs, à exceção de quatro, já que dois reproduzem na íntegra as dos PEs. Os demais PCEs focam a sua intervenção no ambiente da aprendizagem, no trabalho colaborativo, na valorização da relação escola/comunidade - no que respeita à constituição de parcerias ou ao envolvimento das famílias na escola -, na formação dos recursos humanos e na melhoria dos resultados escolares. Nesse sentido e na sequência do acima referido, a ausência de articulação entre os PCEs e os PEs é um aspeto a sublinhar, pois apenas seis escolas referem o PE para definirem as prioridades curriculares.

Os aspetos curriculares essenciais a investir mais, em face das características e necessidades da população, estão presentes na maioria dos PCEs (oito) articulados com a necessidade de garantir a consecução das aprendizagens do currículo tido por nuclear. Nesse sentido, valoriza-se o reforço do ensino e das competências a desenvolver tanto em torno de saberes estruturantes, a saber, a Língua Portuguesa ou a Matemática, como no âmbito da cidadania e das TIC (PORTUGAL, 2012).

As medidas de promoção do sucesso escolar proliferam em todos os PCEs e são variadas, porém, na maioria são entendidas como medidas de remediação aparentemente devidas a limitações prévias e deterministicamente percepcionadas a respeito dos alunos e dos seus contextos, e não a possíveis mudanças ao nível do trabalho pedagógico ou da organização escolar.

Nesse aspeto, os PCEs em análise parecem remeter para alguma dificuldade das respetivas escolas em se conceberem como possíveis instâncias responsáveis pela reprodução de desigualdades educativas, apesar de toda a literatura, desde os Herdeiros de Bourdieu e Passeron (1964), demonstrar empiricamente também a sua contribuição para a manutenção das desigualdades sociais traduzidas em desigualdades educativas. De facto, parece faltar nos PCEs uma leitura sociológica das práticas escolares e pedagógicas que poderia 
ultrapassar o que parece ser uma conceção das medidas de promoção dos resultados escolares, entendidas em termos meramente do deficit cognitivo dos alunos.

Entre as medidas para a promoção do sucesso escolar, destacam-se os apoios educativos, a constituição de grupos de homogeneidade relativa, as atividades de apoio ao estudo (como as salas de estudo) e a diferenciação curricular concebida apenas no âmbito destas medidas de remediação. A medida pedagógica mais referenciada para a melhoria dos resultados escolares é a coadjuvação em sala de aula que está plasmada nos normativos legais (PORTUGAL, 2012).

\section{ORGANIZAÇÃO DAS APRENDIZAGENS}

No que respeita à oferta de aprendizagens em campos não cobertos pelo currículo nacional, as escolas dispõem da possibilidade de introduzir, no $1^{\circ}, 2^{\circ}$ e $3^{\circ}$ ciclos de escolaridade, uma disciplina de Oferta Complementar e, nos $7^{\circ}$ e $8^{\circ}$ anos, além desta, a disciplina de Oferta da Escola (Despacho n. 10-A/2015 de 19 de junho de 2015), em articulação com a disciplina de Tecnologias da Informação e da Comunicação (TIC). Apenas dois PCEs não discriminam a disciplina da Oferta Complementar, porém, esmagadoramente selecionam o ensino da Cidadania com as mais variadas denominações (Formação Cívica, Educação para a Cidadania, Educação para a Saúde e Cidadania, Educação e Cidadania, Desenvolvimento de Competências Pessoais e Sociais, Saber Estar, Literacias e Cidadania). As exceções são dois PCEs que, no $1^{\circ}$ ciclo, oferecem Iniciação à Programação e Ensino Experimental das Ciências e três que, no $3^{\circ}$ ciclo, para além da Cidadania, ainda oferecem Língua e Cultura Alemã, Inglês e Oficina de Escrita e Comunicação, em algum(uns) dos respetivos anos de escolaridade. A justificação mais recorrente, enunciada ou implícita, para a seleção destes saberes é que complementam o currículo prescrito ou os princípios enunciados.

A seleção privilegiada do saber da Cidadania pelas escolas pode dever-se às indicações emanadas da administração central, como sugere o Decreto-Lei n. 139/2012:

[...] pretende-se que a educação para a cidadania enquanto área transversal seja passível de ser abordada em todas 
as áreas curriculares, não sendo imposta como uma disciplina isolada obrigatória, mas possibilitando às escolas a decisão da sua oferta nos termos da sua materialização disciplinar autónoma (PORTUGAL, 2012, preâmbulo).

Na Oferta de Escola, a seleção dos saberes recai nas áreas das Expressões (Educação Tecnológica e Artes), à exceção de Estudos e Projetos Europeus (cidadania europeia), Robótica e Produção de Imagem e Animação, em três PCEs respetivamente. Isso significa que apenas dois PCEs selecionam saberes que não constituem o currículo nacional e que, no caso da Robótica, configura uma aproximação ténue da escola aos saberes ligados à área da sua municipalidade, pela proximidade com um Instituto Politécnico que tem uma forte aposta nesta área.

Na seleção de conhecimento para currículo, as escolas parecem privilegiar saberes que decorrem ou complementam o currículo prescrito.

Nas áreas não disciplinares que incluem as atividades de enriquecimento curricular, os PCEs elencam, em sua maioria, uma enorme variedade de projetos, clubes/oficinas oferecidos, não sujeitos à avaliação, que procuram um enriquecimento das áreas de formação pessoal, científica, artística, desportiva e social dos alunos. As justificações para a seleção destas atividades centram-se no complemento ao currículo prescrito, mas inscrevem-se ainda, embora de forma ténue, na contextualização curricular, procurando a adaptação a certas atividades profissionais ou lúdicas da comunidade (Clube de Xadrez, Clube de Robótica) e também como pretexto para a construção de laços identitários ou como forma de apoio a disciplinas com maus resultados escolares.

Em relação às competências a serem adquiridas pelos alunos, poucos são os PCEs a conceber um conjunto de competências à saída do ensino básico (um PCE) ou secundário (dois PCEs), ou até mesmo um conjunto de competências transversais aos ciclos de ensino (um PCE). Porém, para esta situação pode contribuir o facto de Portugal não ter, no nível da administração central, um perfil de competências desde 2011, 
quando se revogou o Currículo Nacional (Despacho n. 17169/2011, de 23 de dezembro). No sistema português, o carater prescritivo da cultura da administração central e a sua naturalização nas escolas são muito fortes, o que explica esta dependência da prescrição central do currículo.

\section{MÉTODOS E ESTRATÉGIAS DE ENSINO E AVALIAÇÃO}

A filosofia e metodologias de ensino apresentadas como estratégicas, mas depois operacionalizadas nas disciplinas/ anos/ciclos de ensino, que a escola privilegia em função dos valores que assume como sua proposta educativa, estão presentes apenas num PCE que destaca as metodologias ativas, mas equaciona também a expositiva no nível do $1^{\circ}, 2^{\circ}$ e $3^{\circ}$ ciclos e ensino secundário.

As técnicas pedagógicas apenas são referidas em três PCEs, que compreendem o trabalho de grupo, a realização de atividades experimentais e o trabalho de projeto.

Os recursos pedagógicos são equacionados também por três PCEs, que sublinham a integração das TICs na sala de aula. O manual como recurso específico do ensino está fora do registo da gestão curricular. Esta omissão sugere algum questionamento a desenvolver em futuras investigações, uma vez que o manual é o recurso pedagógico básico e mais utilizado na prática dos professores e escolas. A sua não referência pode ser entendida como reflexo de uma naturalização que exclui outras possibilidades, ou uma intenção eventualmente involuntária de ocultação do recurso ao manual como principal fonte do currículo.

Assim, nos métodos e estratégias de ensino, os PCEs são altamente deficitários. As práticas de ensino, que constituem um dos elementos principais do currículo e corporizam o seu desenvolvimento, estão praticamente ausentes, configurando uma contradição entre a natureza do projeto curricular e o seu uso.

A avaliação das aprendizagens dos alunos ocupa um espaço central em todos os PCEs, pela importância, reconhecida em alguns destes documentos, da avaliação como um elemento estruturante do processo de ensino-aprendizagem, quer seja como elemento regulador das práticas pedagógicas, 
quer seja como fator certificador das aprendizagens ou da orientação do percurso escolar, discurso aliás parafraseado a partir dos normativos legais (PORTUGAL, 2012).

A generalidade dos PCEs estabelecem, sobretudo, como modalidades de avaliação, a diagnóstica, formativa e sumativa e, como campos, os conhecimentos, competências e comportamentos/atitudes/valores, apresentando exemplos de vários instrumentos de avaliação. No que respeita à definição do campo dos comportamentos/atitudes/valores, os PCEs apenas mencionam itens a avaliar, como a participação do aluno ou a assiduidade, e nem sempre definem de forma clara o que se pretende com aqueles conceitos.

Dessa forma, como as práticas avaliativas são suscetíveis de diferentes interpretações, suscitadas por entendimentos concetuais divergentes que conduzem a variadas concretizações práticas da avaliação, seria necessário encontrar pontos de convergência facilitados pela clarificação concetual quer do entendimento das modalidades de avaliação, quer do que se entende por comportamentos/atitudes/valores e de que forma são incorporados na avaliação (PACHECO, 2002; HARLEN, 2007; ROLDÃO; FERRO, 2015).

\section{MODOS DE FUNCIONAMENTO E ORGANIZAÇÃO DA ESCOLA E DAS AULAS}

O nível de decisão curricular sobre os modos de funcionamento e organização da escola, no âmbito do enquadramento das atividades de aprendizagem, é uma das partes mais desenvolvidas nos PCEs, sendo preponderantes as matérias sobre as estratégias para a constituição das turmas, os horários dos professores, os horários dos alunos e a distribuição do serviço docente. Constata-se que a maioria das medidas preconizadas consta dos normativos legais, poucas são as medidas avançadas pelas escolas.

As estratégias dirigidas à família e ao município são mais raras, possivelmente por constituírem uma parte significativa dos PEs, como tivemos oportunidade de comprovar a partir da sua consulta.

A gestão estratégica ao nível do espaço das aulas e dos tempos está praticamente ausente nos PCEs. O espaço da 
aula não é concebido numa perspetiva pedagógica, mas especialmente no sentido logístico a julgar pelas medidas elencadas apenas em três PCEs: estabelecer a coabitação limitada de turmas no ginásio; garantir a atribuição de sala própria para disciplinas de cariz mais prático; e fixação de uma sala para cada turma.

Já a gestão dos tempos letivos apresenta-se muito uniforme em todas as escolas, sobretudo organizados em períodos de 45 minutos, sendo que raramente se selecionam diferentes tempos letivos entre ciclos ou entre disciplinas. Porém, nesta matéria a legislação portuguesa é bastante flexível. O Decreto-Lei n. 6/2001, que estabeleceu os princípios orientadores da organização e da gestão curricular do ensino básico, determinava que a carga horária semanal se organizava em múltiplos de 45 minutos, sobretudo, em períodos de 90 minutos (PORTUGAL, 2001a). Uma década mais tarde, o Decreto-Lei n. 139/2012 procedeu a uma revisão de normas para o desenho curricular, de forma a permitir maior autonomia às escolas na organização das atividades letivas, incluindo a não obrigatoriedade, no $2^{\circ}$ e $3^{\circ}$ ciclos, da organização dos horários de acordo com tempos letivos de 45 minutos ou seus múltiplos, desde que as escolas respeitassem as cargas horárias semanais previstas nas matrizes curriculares do ensino básico (PORTUGAL, 2012).

A uniformidade da seleção da unidade de tempo letivo nos PCEs encontra-se em consonância com um estudo recente do Conselho Nacional da Educação (CNE) em parceria com o Projeto Curriculum Monitor desenvolvido no Centro Interdisciplinar de Ciências Sociais da Universidade Nova de Lisboa (ALMEIDA et al., 2017). Este estudo mostra, a partir de uma amostra representativa de escolas do $5^{\circ}$ e $9^{\circ}$ anos do ensino básico de Portugal Continental, no ano letivo de 2015/2016, num total de 231 Unidades Orgânicas (UO), que a maioria dos seus horários apresenta uma carga horária semanal organizada em períodos de 45 minutos (72,7\%), seguindo-se os tempos letivos de 50 minutos $(25,5 \%)$. Como podemos verificar pela Tabela 1, apenas duas UO organizam os tempos por unidades de 60 minutos, uma por unidades de 70 minutos e outra por tempos diferenciados nos $5^{\circ}$ e $9^{\circ}$ anos e por disciplinas. 
TABELA 1 - Unidade de tempo letivo nas Unidades Orgânicas e nas turmas de $5^{\circ}$ e $9^{\circ}$ anos de escolaridade. $2015 / 2016$

\begin{tabular}{|c|c|c|c|c|c|c|c|c|c|c|c|}
\hline \multirow{3}{*}{$\begin{array}{l}\text { UNIDADES } \\
\text { ORGÂNICAS }\end{array}$} & \multicolumn{10}{|c|}{ UNIDADE DE TEMPO LETIVO } & \multirow{3}{*}{ TOTAL } \\
\hline & \multicolumn{2}{|c|}{45 MINUTOS } & \multicolumn{2}{|c|}{50 MINUTOS } & \multicolumn{2}{|c|}{60 MINUTOS } & \multicolumn{2}{|c|}{70 MINUTOS } & \multicolumn{2}{|c|}{ DIFERENCIADO } & \\
\hline & $\mathrm{N}$ & $\%$ & $\mathrm{~N}$ & $\%$ & $\mathrm{~N}$ & $\%$ & $\mathrm{~N}$ & $\%$ & $\mathrm{~N}$ & $\%$ & \\
\hline $\begin{array}{l}\text { Sem contrato de } \\
\text { autonomia }\end{array}$ & 128 & 71,91 & 47 & 26,40 & 2 & 1,12 & 0 & 0,00 & 1 & 0,56 & 178 \\
\hline $\begin{array}{l}\text { Com contrato de } \\
\text { autonomia }\end{array}$ & 40 & 75,47 & 12 & 22,64 & 0 & 0,00 & 1 & 1,89 & 0 & 0,00 & 53 \\
\hline Total & 168 & 72,73 & 59 & 25,54 & 2 & 0,87 & 1 & 0.43 & 1 & 0.43 & 231 \\
\hline
\end{tabular}

Fonte: CNE e Projeto Curriculum Monitor, 2017.

Em relação às justificações para a escolha da unidade de tempo letivo, apesar de nos PCEs se acumularem páginas com as matrizes curriculares com os tempos das disciplinas, apenas um PCE justifica sua opção pelos 45 minutos com base numa maior concentração das atividades letivas no período da manhã (seis tempos) e numa melhor gestão da afetação da carga horária por disciplina e área disciplinar.

Os princípios enquadradores das opções organizativas do trabalho dos professores, designadamente o trabalho colaborativo a começar pela articulação vertical, são mencionados pela quase totalidade dos PCEs, sendo a realização/ planificação de atividades comuns, a troca de informações sobre processos dos alunos e a garantia da sequencialidade das aprendizagens, as práticas mais referenciadas, seguidas pela respetiva calendarização.

Já a articulação horizontal apresenta uma fraca presença nos PCEs, a acrescer à ausência completa de calendarização das poucas medidas avançadas, o que, ao contrário da articulação vertical, pode significar uma prática ainda pouco enraizada no quotidiano destas escolas. A articulação horizontal parece remeter mais para um discurso retórico induzido pela avaliação externa das escolas por não ser sustentado, na maioria dos casos, em medidas concretas e respetiva calendarização, mas sim por expressões que implicam a necessidade de "Reunir para a interdisciplinaridade" (ALMEIDA, 2017); ou, ainda, reenviar para o "efeito transformador" falacioso da "bondade dos princípios" (BARROSO, 2014), um equívoco recorrente nas práticas da escola e dos professores, 
3 Programa lançado pelo Ministério da Educação, em 2006, com objetivo central de elevar os níveis de literacia dos portugueses colocar o país no nível do contexto europeu. Nas escolas do ensino básico e secundário materializa-se num conjunto de medidas e apoios financeiros para estimular nos alunos o prazer da leitura, intensificando o contacto com o livro na escola, seja nas salas de aula, seja nas respetivas bibliotecas. Consultar Alçada (2006). ao acreditar-se que determinados conceitos/princípios enunciados nos documentos reguladores (não operacionalizados) atribuem aos seus destinatários capacidade de ação.

As medidas de articulação da biblioteca escolar com o trabalho pedagógico têm alguma presença nos PCEs, possivelmente pela adesão das escolas ao Plano Nacional de Leitura lançado pelo governo em $2006 .{ }^{3}$ Em três PCEs, regista-se a existência de articulação entre a educação literária desenvolvida nas salas de aula e as iniciativas desenvolvidas pela biblioteca escolar, no âmbito do Plano Nacional de Leitura. Outras formas de articulação com a biblioteca escolar são sugeridas pela disponibilização de apoio pedagógico a professores e pela realização de atividades em articulação com as práticas letivas, como o apoio às matérias correntes nas salas de aulas fornecendo materiais de consulta atualizados aos alunos.

A articulação entre as áreas disciplinares e não disciplinares raramente se inscreve no registo dos PCEs e, tal como a articulação com a biblioteca escolar, não é referida a calendarização para eventuais reuniões.

A formação dos professores é outra dimensão pouco sublinhada nos PCEs: apenas duas escolas estabelecem as áreas de formação a investir, mas sem agendar calendarização para qualquer uma delas.

\section{A AVALIAÇÃO DO RESULTADO DAS OPÇÕES DO PROJETO CURRICULAR}

Em relação à avaliação da gestão curricular preconizada nos PCEs, esta parece pouco naturalizada na cultura destas escolas. Os campos de avaliação são mencionados por metade das escolas e caraterizam-se pela sua limitação, restringindo-se ao trabalho pedagógico desenvolvido nas turmas ou apenas às orientações nos documentos não seguidas pelos atores educativos. A maioria dos PCEs menciona a necessidade da sua avaliação periódica, mas raramente especifica a calendarização, indicadores ou os responsáveis pela prática avaliativa.

Com efeito, a avaliação dos PCEs configura uma parte fraca dos campos de decisão curricular que, por não serem concebidos essencialmente como um conjunto de ações estratégicas, dificilmente são passíveis de avaliação. 
Desde logo, o registo escrito dos PCEs deixa perceber que estas escolas ainda não se apropriaram do conceito de projeto. Este facto é, em parte, explicável pela lista de informações/definições nos PCEs, ora com disposições normativas para os docentes, ora com disposições sobre a organização da escola, como vimos no Quadro 2, oscilando entre o registo escrito do regulamento e do relatório, que ocupa uma parte substancial destes documentos, como podemos verificar pelos dois exemplos de Document Portrait ${ }^{4}$ (Figuras 1 e 2).

Figura 1 - Document Portrait: Projeto curricular n. 3

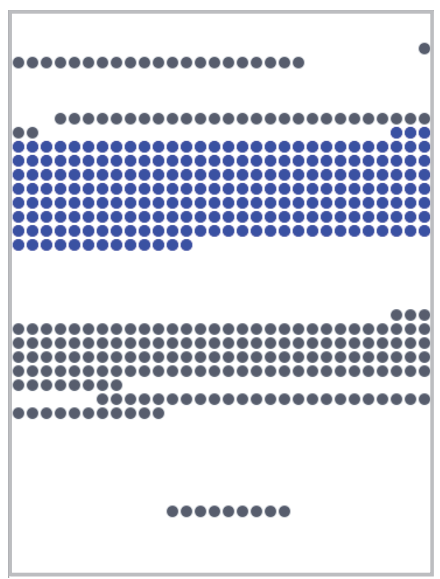

Figura 2 - Document Portrait: Projeto curricular n. 5

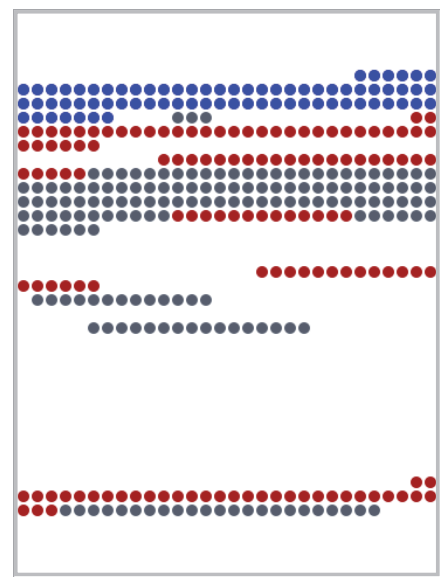

4 Document Portrait é uma imagem total de cada documento em análise, que mostra tanto a sequência de categorias ou subcategorias que selecionamos para visualizar, como a percentagem que os segmentos de texto alocados naquelas ocupam na totalidade de cada documento analisado.

\section{Legenda \\ Code \\ Disposições normativas para os docentes Disposições sobre a organização da escola Matrizes curriculares}

Fonte: 12 Projetos Curriculares de Escola/agrupamento de uma rede de escolas portuguesas. Realizado em MAXQDA 12.3.1.

Em síntese, a análise avaliativa destes PCEs, intencionalizados na sua criação e prescrição como documentos de gestão estratégica, operacionalizadores supostamente do Projeto da Escola ou agrupamento no que se refere à dimensão curricular, revela escasso potencial estratégico, nomeadamente pelas seguintes características que a análise de conteúdo destes 12 PCEs permitiu destacar:

- caráter descritivo da organização sem retirar dela nem fundamentos nem implicações no plano pedagógico e curricular; 
- proximidade a documento normativo pela inclusão de direitos, tempos atribuídos a tarefas e outras medidas de natureza regulamentar;

- invisibilidade quase total de opções da escola no plano curricular, limitadas à adoção de áreas transversais no campo da cidadania, à inclusão de algumas áreas complementares e ao reforço de tempos de trabalho para alunos com dificuldades nas áreas assumidas como estruturantes, como a Matemática e o Português;

- ausência maioritária de decisões relativas a modos de trabalho de professores ou a estratégias de ensino e aprendizagem preconizadas de forma estratégica;

- escassa visibilidade de orientações para o papel regulador da avaliação no desenvolvimento e melhoria das aprendizagens curriculares, expressando contudo de forma nominal as tipologias diagnóstica, formativa e sumativa, e sendo referidos genericamente os campos a abordar;

- insuficiência de elementos sobre avaliação do próprio projeto curricular, explicável em parte pelo facto de as ações e opções estratégicas serem pouco operacionalizadas, o que não possibilita sua análise avaliativa;

- difícil identificação de usos eficazes deste instrumento na melhoria do desempenho da escola e dos professores.

A natureza prescritiva da produção deste tipo de documentos, articulada com uma escassa tradição de autonomia na condução do ensino por parte das escolas, e ainda a tradição predominante de trabalho docente em lógica individual configuram explicações possíveis para esta escassa valia estratégica de instrumentos de gestão contextualizada do currículo que, todavia, ocupam grande quantidade de tempo e esforço na sua produção, sem correspondente evidência do seu impacto na transformação das rotinas da escola e na melhoria da sua eficácia curricular. 


\section{REFERÊNCIAS}

AINSCOW, M. (Ed.). Effective schools for all. London: David Fulton, 1991.

ALÇADA, I. (Coord.). Plano Nacional de Leitura: relatório síntese. Lisboa: Ministério da Educação, 2006.

ALMEIDA, S. de. Modos de apropriação das políticas educativas para uma gestão curricular contextualizada. In: CONGRESSO PORTUGUÊS DE SOCIOLOGIA, 9., 2017, Faro, PT. Atas... Faro, Portugal: Universidade do Algarve/Faculdade de Economia, 2017. p. 1281-1307.

ALMEIDA, S. de et al. Organização escolar: o tempo. Lisboa: Conselho Nacional da Educação, 2017.

ANANIADOU, K.; CLARO, M. 21st century skills and competences for new millennium learners. Paris: OECD, 2009. (OECD Education Working Papers, n. 41).

BARBIER, J.-M. Élaboration de projets d' action et planification. Paris: PUF, 1991.

BARDIN, L. Análise de conteúdo. 4. ed. Lisboa: Edições 70, 2006. Conforme edição de 1977.

BARROSO, J. Fazer da escola um projeto. In: CANÁRIO, R. (Org.). Inovação e projeto educativo da escola. Lisboa: Educa, 1992. p. 17-55.

BARROSO, J. Para o desenvolvimento de uma cultura de participação na escola. Lisboa: Instituto de Inovação Educacional, 1995. (Cadernos de Organização e Gestão Escolar, n. 1).

BARROSO, J. Autonomia e gestão das escolas. Lisboa: Ministério da Educação, 1997.

BARROSO, J. Autonomia, contratos e direção das escolas. In: MACHADO, J.; ALVES, J. M. (Org.). Melhorar a Escola-Educação para Todos: igualdade, diversidade e autonomia. Porto: Universidade Católica Editora, 2014. p. 91-111.

BARROSO, J. ; SJORSLEV S. Administration and evaluation structures for primary and secondary schools in the twelve member states of the EC. Brussels: Eurydice, 1990.

BENAVOT, A.; BRASLAVSKY, C. (Ed.). School knowledge in comparative and historical perspective. Changing curricula in the primary and secondary education. Dordrecht, The Netherlands: Springer, 2007.

BOURDIEU, P.; PASSERON, J. C. Les héritiers: les étudiants et la culture. Paris: Minuit, 1964.

CACHAPUZ, F. et al. (Org.). Saberes básicos de todos os cidadãos no século XXI. Lisboa: Conselho Nacional de Educação, 2004. (Estudos e Relatórios).

CARMEN, L. del; ZABALA, A. Guia para la elaboracion, seguimento y valoracion de proyectos curriculares de centro. Madrid: Cide, 1991. 
CLARK, C. et al. Theories of inclusion, theories of schools: deconstructing and reconstructing the "inclusive school". British Educational Research Journal, v. 25, n. 2, p. 157-176, 1999.

COSTA, J.; RAMOS, M. Os professores e a (re)construção do currículo na escola: a construção de projetos curriculares de escola e de turma. In: COSTA, J. A. et al. Gestão curricular: percursos de investigação. Aveiro: Universidade de Aveiro, 2004. p. 79-97.

CUBAN, L. A fundamental puzzle of school reform. In: LIEBERMAN, A. (Ed.). Schools as colleborative cultures: creating the future now. New York: The Falmer, 1990. p. 71-77.

FINNISH NATIONAL BOARD OF EDUCATION. National Curriculum. Helsinki: FNBE, 2016.

GIMENO, J. El curriculum: una reflexión sobre la prática. Madrid: Morata, 1989.

GODET, M. Prospective et planification stratégique. Paris: Economica, 1985.

GODET, M. Prospective et stratégie: approches intégrées. Futuribles, novembro 1989.

GONÇALVES, A. M.; MORGADO, J. C. Construção de um projeto curricular de escola: perceções e predisposições dos professores. 2013. Disponível em: $<$ http://hdl.handle.net/1822/23181>. Acesso em: 18 maio 2017.

GOODSON, I. The making of curriculum. London: Falmer, 1988.

GOODSON, I. Learning, curriculum and life politics. The selected works of I. Goodson. Abingdon, Great Britain: Routledge, 2005.

HARLEN, W. Criteria for evaluating systems for student assessment. Studies in Educational Evaluation, v. 33, n. 1, p. 15-28, 2007.

HATTIE, J. Visible learning: a synthesis of 800 meta-analyses relating to achievement. London: Routledge, 2009.

HUTMACHER, W. A escola em todos os seus estados: das políticas de sistemas às estratégias de estabelecimento. In: NÓVOA, A. (Coord.). As organizações escolares em análise. Lisboa: Educa, 1992. p. 45-76.

KUCKARTZ, U. Qualitative text analysis. A guide to methods, practice and using software. London: Sage, 2014.

LE BOTERF, G. De la compétence. Essai sur un attracteur étrange. Paris: Les Éditions d'Organization, 1994.

MORGADO, J. C. Projeto curricular e autonomia da escola: possibilidades e constrangimentos. Revista Galego-Portuguesa de Psicología e Educación, v. 8, n. 10, p. 335-344, 2003.

MORGADO, J. C. Projeto curricular e autonomia da escola: das intenções às práticas. Revista Brasileira de Política e Administração da Educação, v. 27, n. 3, p. 361-588, 2011. 
MORGADO, J. M.; MARTINS, F. B. Projecto curricular: mudança de práticas ou oportunidade perdida? Revista de Estudos Curriculares, v. 6, n. 1, p. 3-19, 2008.

ORGANISATION FOR ECONOMIC CO-OPERATION AND DEVELOPMENT. Environnement, école et pédagogie active. Paris: OECD/CERI, 1991.

ORGANISATION FOR ECONOMIC CO-OPERATION AND DEVELOPMENT. La réforme des programmes scolaires: l'évaluation en question. Paris: OECD/CERI, 1993.

ORGANISATION FOR ECONOMIC CO-OPERATION AND DEVELOPMENT. The curriculum redefined: schooling for the 21st century. Paris: OECD/CERI, 1994.

ORGANISATION FOR ECONOMIC CO-OPERATION AND DEVELOPMENT. Making the curriculum work. Paris: OECD/CERI, 1998.

ORGANISATION FOR ECONOMIC CO-OPERATION AND DEVELOPMENT. Innovating schools (Schooling for tomorrow project). Paris: OECD/CERI, 1999.

ORGANISATION FOR ECONOMIC CO-OPERATION AND DEVELOPMENT. Trends shaping education. Paris: OECD, 2013.

ORGANISATION FOR ECONOMIC CO-OPERATION AND DEVELOPMENT. TALIS 2013 Results: an international perspective on teaching and learning. Paris: OECD Documents, 2014.

ORGANISATION FOR ECONOMIC CO-OPERATION AND DEVELOPMENT. Towards defining character/attitudes/values/behaviours. In: EDUCATION 2030 WORKSHOP, 16 November 2015. Paris: OECD, 2015. (EDU/

EDPC/M(2015)5: Education Working Papers, n. 41). Draft summary.

ORGANISATION FOR ECONOMIC CO-OPERATION AND DEVELOPMENT. Education 2030 International Curriculum Analysis: Twenty Years of Background Analysing Mathematics and Science Curricula. In: MEETING OF THE INFORMAL WORKING GROUP OF THE FUTURE OF EDUCATION AND SKILLS, 3 ${ }^{\text {rd. }}$ 3-4 May 2016, Paris, France. Annals... Paris: OECD, 2016.

ORGANISATION FOR ECONOMIC CO-OPERATION AND DEVELOPMENT. Project "Future of education and skills: education 2030". Paris: OECD, 2017. (OECD Working papers).

PACHECO, J. A. Projeto curricular integrado. Lisboa: Ministério da Educação, 1998. (PEPT 2000, n. 18).

PACHECO, J. A. Critérios de avaliação na escola. In: ABRANTES, P.; ARAÚJO, F. (Org.). Avaliação das aprendizagens: das concepções às práticas. Lisboa: Ministério da Educação, DEB, 2002. p. 55-64.

PACHECO, J. A.; MORGADO, J. C. Construção e avaliação do projeto curricular de escola. Porto: Porto, 2002.

PACHECO, J. A.; PEREIRA, N. Estudos curriculares: das teorias aos projetos de escola. Educação em Revista, n. 45, p. 197-221, 2007.

PERRENOUD, P. Construire des compétences dés l'école. Paris: ESF, 1997. 
PERRENOUD, P. Novas competências para ensinar. São Paulo: Artmed, 2000.

PORTUGAL. Ministério da Educação. Decreto-Lei n. 43, de 3 de fevereiro de 1989. Diário da República, Lisboa, n. 29/1989, Série I, 3 fev. 1989.

PORTUGAL. Ministério da Educação. Departamento da Educação Básica. Relatório do Projeto "Reflexão participada sobre os Currículos do Ensino Básico". Lisboa: ME-DEB, 1997.

PORTUGAL. Ministério da Educação. Decreto-Lei n. 6, de 18 de janeiro de 2001. Diário da República, Lisboa, n. 15/2001, Série I-A, 18 jan. 2001a.

PORTUGAL. Ministério da Educação. Currículo nacional do ensino básico competências essenciais. Lisboa: Ministério da Educação, 2001b.

PORTUGAL. Ministério da Educação. Decreto-Lei n. 139, de 5 de julho de 2012. Diário da República, Lisboa, n. 129/2012, Série I, 5 jul. 2012.

RED JESUÏTES EDUCACIÓ. Projeto Horizonte 2020. Barcelona, 2015.

RODRIGUES, M.; SÁ-CHAVES, I. Gestão curricular e cultura de escola: a relação entre as dimensões curriculares instituída e instituinte. In: COSTA, J. et al. Gestão curricular, percursos de investigação. Aveiro: Universidade de Aveiro, 2004. p. 69-87.

ROLDÃO, M. C. 0 diretor de turma e a gestão curricular. Lisboa: Instituto de Inovação Educacional, 1995. (Cadernos de Organização e Gestão Escolar, n. 2).

ROLDÃO, M. C. Currículo: um processo de construção, gestão e formação reflexiva centrado na escola. In: ENCONTRO DE INVESTIGAÇÃO EM EDUCAÇÃO MATEMÁTICA, 6., 6, 7 e 8 de abril de 1997, Castelo de Vide. Actas... Portalegre: SPCE, 1998. p. 31-39.

ROLDÃO, M. C. Currículo como projeto: o papel das escolas e dos professores. In: MARQUES, R.; ROLDÃO, M. C. (Org.). Reorganização e gestão curricular no ensino básico. Porto: Porto, 1999a. p. 11-21.

ROLDÃO, M. C. Gestão curricular. Fundamentos e práticas. Lisboa: Ministério da Educação, Departamento de Educação Básica, 1999b.

ROLDÃO, M. C. Os professores e a gestão do currículo: perspetivas e práticas em análise. Porto: Porto, 1999c.

ROLDÃO, M. C. O currículo escolar: da uniformidade à contextualização campos e níveis de decisão curricular. Revista de Educação, v. 9, n. 9, p. 81-92, 2000.

ROLDÃO, M. C. A escola como instância de decisão curricular. In: ALARCÃO, I. (Org.). Escola reflexiva e supervisão: uma escola em desenvolvimento e aprendizagem. Porto: Porto, 2001. p. 67-77. (CIDInE, n. 14).

ROLDÃO, M. C. Avaliação de competências e gestão do currículo: as questões dos professores. Lisboa: Presença, 2003a.

ROLDÃO, M. C. Diferenciação curricular revisitada: conceito, discurso e práxis. Porto: Porto, 2003b. 
ROLDÃO, M. C. Formação e práticas de gestão curricular: crenças e equívocos. Porto: Asa, 2005a.

ROLDÃO, M. C. Para um currículo do pensar e do agir: as competências enquanto referencial de ensino e aprendizagem. En Direct de l'APPF, suplemento, p. 9-20, fev. 2005b.

ROLDÃO, M. C. A função curricular da escola e o papel dos professores: políticas, discurso e práticas de contextualização e diferenciação curricular. In: COLÓQUIO LUSO-BRASILEIRO DAS QUESTÕES CURRICULARES, 4., Florianópolis, Brasil, setembro de 2008. Anais... Florianópolis: Universidade Federal de Santa Catarina, 2008.

ROLDÃO, M. C. Currículo, formação e trabalho docente. In: SANTOS, L. L. C. P.; FAVACHO, A. M. P. (Org.). Políticas e práticas curriculares: desafios contemporâneos. Curitiba, Brasil: CRV, 2012. p. 65-79.

ROLDÃO, M. C. Currículo, didáticas e formação de professores - a triangulação esquecida? In: OLIVEIRA, M. R. (Org.). Professor: formação, saberes e problemas. Porto: Porto, 2014. p. 91-103.

ROLDÃO, M. C. Currículo enquanto conhecimento necessário: eixos de uma discussão. In: CONSELHO NACIONAL DA EDUCAÇÃO. Pareceres e Conferências. Lisboa: CBE, 2016.

ROLDÃO, M. C.; FERRO, N. O que é avaliar? Reconstrução de práticas e conceções de avaliação. Estudos em Avaliação Educacional, v. 26,

n. 63, p. 570-594, set./dez. 2015.

SACRISTÁN, J. G. El curriculum: una reflexión sobre la práctica. 4, ed. Madrid: Morata, 1994.

SKILBECK, M. Curriculum reform: an overview of trends. Paris: OECD, 1990.

SKILBECK, M. The core curriculum. In: ORGANISATION FOR ECONOMIC CO-OPERATION AND DEVELOPMENT. The curriculum redefined: schooling for the 21st century. Paris: OECD, 1994. p. 95-100.

TARDIF, J. Le transfert des compétences analysé à travers la formation de professionels. In: MEIRIEU, P. et al. (Ed.). Le concept de transfert de connaissances en formation initiale et en formation continue. Lyon: CRDP, 1996. p. 55-72.

TYACK, D.; CUBAN, L. Tinkering toward utopia. A century of public school reform. Cambridge: Harvard University, 1995.

UNITED NATIONS EDUCATIONAL, SCIENTIFIC AND CULTURAL ORGANIZATION. Curriculum in the twenty-first century: challenges, tensions and open questions. Paris: Unesco Education Research and Foresight, 2014. (ERF Working Papers, n. 9). Disponível em: <http://unesdoc.unesco.org/ images/0022/002294/229458e.pdf>. Acesso em: 10 maio 2017.

UNITED NATIONS EDUCATIONAL, SCIENTIFIC AND CULTURAL

ORGANIZATION. The curriculum in debates and in educational reforms to 2030: for a curriculum agenda of the twenty-first century, Geneva, 2015. (IBE Working Papers on Curriculum Issues, n. 15). 
UNITED NATIONS EDUCATIONAL, SCIENTIFIC AND CULTURAL

ORGANIZATION. Repensar a educação: rumo a um bem comum mundial?

Brasília, DF: Unesco, 2016.

YOUNG, M. The curriculum of the future. From the new sociology of education to a critical theory of learning. London: Falmer, 1998.

ZABALZA, M. Do currículo ao projeto da escola. In: CANÁRIO, R. (Org.). Inovação e projeto educativo de escola. Lisboa: Educa, 1992. p. 87-107.

MARIA DO CÉU ROLDÃO

Investigadora integrada do Centro de Estudos em

Desenvolvimento Humano da Universidade Católica

Portuguesa (CEDH/UCP), Porto, Portugal

mrceuroldao@gmail.com

\section{SÍLVIA DE ALMEIDA}

Investigadora integrada do Centro Interdisciplinar de Ciências Sociais da Universidade Nova de Lisboa (CICS.NOVA-UNL). Professora auxiliar convidada da Faculdade de Ciências Sociais e Humanas da Universidade Nova de Lisboa (FCSH-UNL), Lisboa, Portugal silvia.almeida@fcsh.unl.pt 
ANEXO 1 - Sistema de categorias

\begin{tabular}{|c|c|}
\hline CAMPOS DE DECISÃO CURRICULAR & CATEGORIAS \\
\hline \multirow[t]{2}{*}{ 1. Filosofia distintiva e oferta educativa } & Especificidade face à oferta educativa \\
\hline & Especificidade face aos métodos de ensino \\
\hline \multirow[t]{3}{*}{ 2. Opções e prioridades } & Aspetos do core curriculum a investir \\
\hline & Referências às orientações/programas/metas curriculares \\
\hline & Medidas de promoção do sucesso escolar \\
\hline \multirow[t]{5}{*}{ 3. Organização das aprendizagens } & Seleção de um perfil de competências \\
\hline & Justificação da seleção da oferta complementar \\
\hline & Justificação da seleção da Oferta da Escola \\
\hline & Justificação da seleção dos projetos \\
\hline & Justificação da seleção dos clubes/oficinas \\
\hline \multirow[t]{7}{*}{ 4. Métodos e estratégias de ensino e avaliação } & Métodos pedagógicos \\
\hline & Técnicas pedagógicas \\
\hline & Recursos pedagógicos \\
\hline & Princípios orientadores da avaliação \\
\hline & Finalidades da avaliação \\
\hline & Modalidades de avaliação das aprendizagens \\
\hline & Campos da avaliação \\
\hline \multirow{13}{*}{$\begin{array}{l}\text { 5. Modos de funcionamento e organização da escola e } \\
\text { das aula }\end{array}$} & Estratégias da constituição de turmas \\
\hline & Estratégias da constituição dos horários dos professores \\
\hline & Estratégias da constituição dos horários dos alunos \\
\hline & Estratégias da distribuição do serviço docente \\
\hline & Estratégias relativas à família \\
\hline & Estratégias relativas ao município \\
\hline & Estratégias sobre a unidade de tempo letivo \\
\hline & Estratégias relativas aos espaços \\
\hline & Articulação das áreas disciplinares e não disciplinares \\
\hline & Articulação horizontal \\
\hline & Articulação vertical \\
\hline & Articulação com a biblioteca escolar \\
\hline & Formação dos docentes \\
\hline $\begin{array}{l}\text { 6. Avaliação do resultado de cada uma das opções do } \\
\text { projeto curricular }\end{array}$ & Campos de avaliação do trabalho curricular \\
\hline
\end{tabular}

Fonte: 12 Projetos Curriculares de Escola/agrupamento de uma rede de escolas portuguesas. 
ANEXO 2 - Variáveis de documento

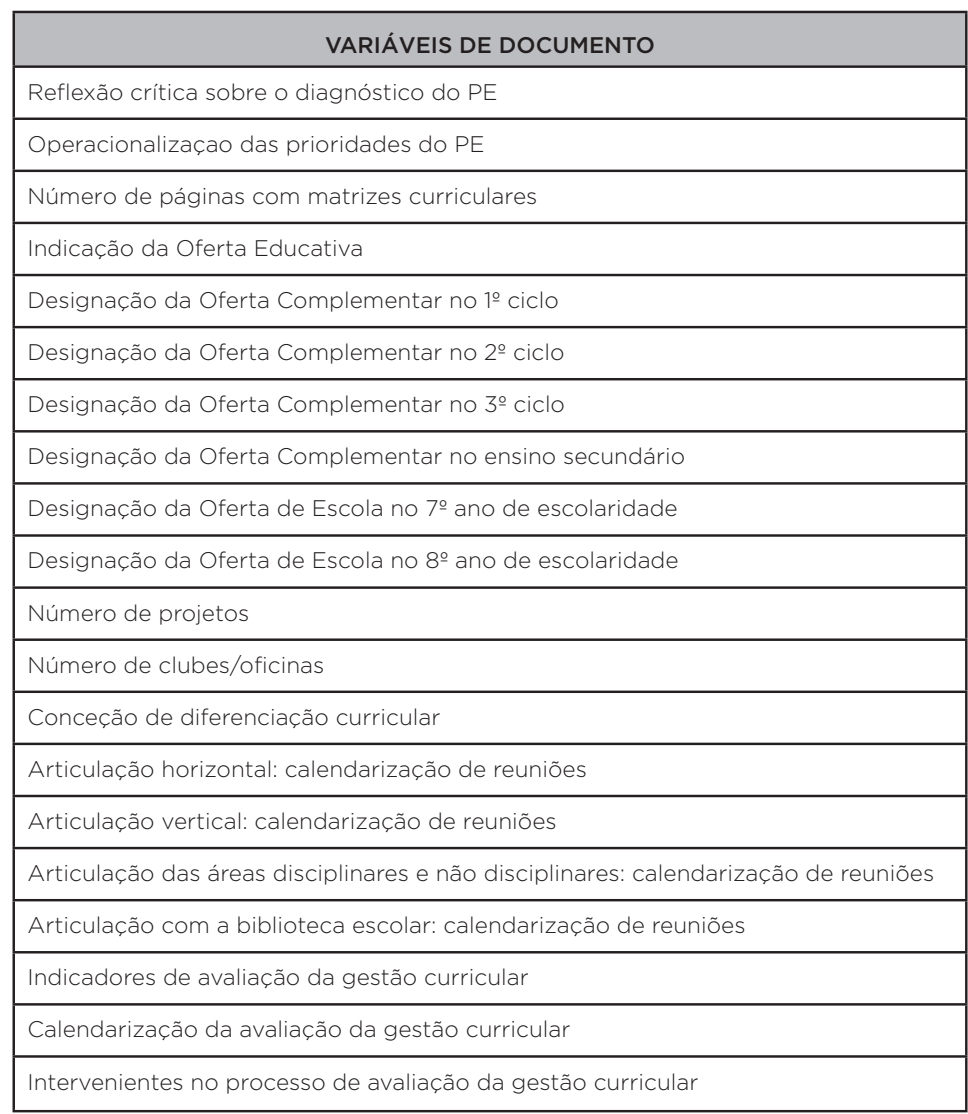

Fonte: 12 Projetos Curriculares de Escola/agrupamento de uma rede de escolas portuguesas.

Recebido em: 08 JUNHO 2017

Aprovado para publicação em: 26 JULHO 2017 
